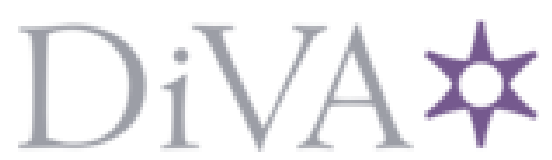

http://www.diva-portal.org

\title{
Postprint
}

This is the accepted version of a paper published in Aquatic Toxicology. This paper has been peerreviewed but does not include the final publisher proof-corrections or journal pagination.

Citation for the original published paper (version of record):

Kellner, M., Porseryd, T., Porsch-Hallstrom, I., Hansen, S., Olsén, H. (2015)

Environmentally relevant concentrations of citalopram partially inhibit feeding in the three-spine stickleback (Gasterosteus aculeatus).

Aquatic Toxicology, 158: 165-170

http://dx.doi.org/10.1016/j.aquatox.2014.11.003

Access to the published version may require subscription.

N.B. When citing this work, cite the original published paper.

NOTICE: this is the author's version of a work that was accepted for publication in Aquatic Toxicology. Changes resulting from the publishing process, such as peer review, editing, corrections, structural formatting, and other quality control mechanisms may not be reflected in this document. Changes may have been made to this work since it was submitted for publication. A definitive version was subsequently published in Aquatic Toxicology,Vol. 158, 165-170. DOI: 10.1016/ j.aquatox.2014.11.003

Permanent link to this version:

http://urn.kb.se/resolve?urn=urn:nbn:se:sh:diva-25351 


\section{Environmentally relevant concentrations of citalopram partially inhibits feeding in the three-spine stickleback (Gasterosteus aculeatus)}

5 Kellner, $\mathrm{M}^{\mathrm{a}^{*}}$., Porseryd, T. ${ }^{\mathrm{a}}$, Porsch-Hällström, I. ${ }^{\mathrm{a}}$, Hansen, S. H', Olsén, K. H. ${ }^{\mathrm{a}}$

"Corresponding author. E-mail: martin.kellner@sh.se

Tel: $+46(0) 86084502$

$10 \quad{ }^{a}$ Department of Natural Sciences, Environment and Technology, Södertörn University, SE14189 Huddinge, Sweden.

${ }^{b}$ Department of Pharmacy, Faculty of Health and Medical Sciences, University of Copenhagen Universitetsparken 2, DK-2100 Copenhagen, Denmark.

Abstract

Selective Serotonin Re-uptake Inhibitors (SSRI) are mood-altering, psychotropic drugs commonly used in the treatment of depression and other psychological illnesses. Many of them are poorly degraded in sewage treatment plants and enter the environment unaltered. In laboratory studies,

20 they have been demonstrated to affect a wide range of behaviours in aquatic organisms. In this study we investigated the effect of a three week exposure of 0.15 and $1.5 \mu \mathrm{g} / \mathrm{l}$ of the SSRI citalopram dissolved in the ambient water on the feeding behaviour in three-spine stickleback (Gasterosteus aculeatus). Feeding, measured as the number of attacks performed on a piece of frozen bloodworms during a 10 minute period, was reduced by $40-60 \%$ in fish exposed to both 0.15 and $1.5 \mu \mathrm{g} / \mathrm{l}$ citalopram. The effects of the environmentally relevant dose $0.15 \mu \mathrm{g} / 1$ on feeding, an important fitness characteristic, suggests that the ecological significance of environmental SSRI exposure may be pronounced.

Keywords: Serotonin, Citalopram, three-spine stickleback, SSRI, feeding, antidepressant

\section{Introduction}

SSRIs (Selective Serotonin Re-uptake Inhibitors) are a class of mood altering, psychotropic drugs which are used in the treatment of several psychiatric diseases such as depression and obsessivecompulsive disorder. Many SSRIs are persistent in the environment (Kwon and Armbrust, 2005) and pass through sewage treatment plants (STPs) with very little or no degradation taking place (Vasskog et al., 2006). Citalopram and other SSRIs are frequently found in STP effluents and have been reported in concentrations between 0.02 and $840 \mu \mathrm{g} / \mathrm{l}$ (Larsson et al., 2007; Vasskog et al.,

40 2008). They are commonly found in natural waters around the world (Fick et al., 2009; Vasskog et al., 2008; Woldegiorgis, A., 2011) and have been recorded in concentrations ranging from $0.5 \mathrm{ng} / 1$ to extremes around $76 \mu \mathrm{g} / \mathrm{l}$ (Fick et al., 2009).

SSRIs act on the serotonergic system which is highly evolutionarily conserved and is present in

45 both vertebrates and invertebrates. The primary mode of action of SSRI is blockade of serotonin (5HT) re-uptake into the pre-synaptic nerve ending, causing an elevated concentration of serotonin in 
the synaptic cleft. Serotonin is involved in a vast array of systems in the body and is known to affect satiety (Grignaschi et al., 1998; Ward et al., 1999), mood parameters such as aggression (Ricci and Melloni, 2012) and locomotor activity (Clissold et al., 2013; Olsén et al., 2014). In humans, sexual

50 dysfunction is a common result of elevated serotonin levels (Keltner et al., n.d.) and suppressed serotonin levels cause clinical depression (Van Praag, 1977). The effects of serotonin are exerted by serotonin binding on a number of 5-HT receptors with different functions, most of which transduce the serotonergic signal through $\mathrm{G}$ proteins (Hoyer et al., 2002). Human serotonin receptors are divided into seven different families and several families contain more than one receptor.

Many of the 5-HT receptors present in humans are also present in fish and accordingly, many of the effects of SSRIs and elevated serotonin levels found in mammals have also been detected in fish. SSRIs decrease territorial aggression (Lepage et al., 2005; Perreault et al., 2003) and the ability or willingness to catch prey is suppressed (Gaworecki and Klaine, 2008). Latency to the initiation

60 of escape response is prolonged, escape velocity is lower (Painter et al., 2009) and SSRI treated piauçu fish (Leporinus macrocephalus) fail to react to a conspecific alarm substance (Barbosa et al., 2012).

The serotonergic system is also vital to the regulation of satiety and feeding. This regulation takes place at least partly in the hypothalamus (Steffens et al., 2010). In rats, intraperitoneal injection of citalopram has an anorectic effect(Grignaschi et al., 1998). Blockade of the 5- $\mathrm{HT}_{1 \mathrm{~A}}$ receptor potentiates this effect (Grignaschi et al., 1998), probably through negative feedback on serotonin release from pre-synaptic 5- $\mathrm{HT}_{1 \mathrm{~A}}$ receptors. Blockade of the $5-\mathrm{HT}_{2 \mathrm{~B} / \mathrm{C}}$ receptors antagonised the inhibitory effect on feeding caused by the combination of citalopram and a $5-\mathrm{HT}_{1 \mathrm{~A}}$ antagonist,

70 suggesting that the hypophagic effect of citalopram is partially mediated by those receptors (Grignaschi et al., 1998). A more detailed picture is revealed by a recent study on rainbow trout (Oncorhynchus mykiss) in which stimulation of 5- $\mathrm{HT}_{1 \mathrm{~A}}$ and $5-\mathrm{HT}_{2 \mathrm{C}}$ receptors had a negative effect on food intake while stimulation of the 5- $\mathrm{HT}_{2 \mathrm{~B}}$ receptor increased food intake (Pérez Maceira et al., 2014). Thus, the regulation of feeding and satiety is complex and the serotonergic system is heavily

75 involved in this regulation. In rodents (Boisvert et al., 2011) and fish (De Pedro N et al., 1998; Ortega et al., 2013), the effect of serotonin on feeding and satiety is at least in part mediated by the Corticotropin Releasing Hormone (CR) system. CRH is also known as the Corticotropin Releasing Factor (CRF) In tilapia (Oreochromis mossambicus ), in vitro stimulation of telencephalic tissue by serotonin causes CRH release (Pepels, 2004). In goldfish (Carassius auratus ) and rainbow trout

80 (Oncorhynchus mykiss) (De Pedro N et al., 1998; Ortega et al., 2013) the Corticotropin Releasing Factor $(\mathrm{CRF})$ receptor antagonist $\alpha$-helical $\mathrm{CRF}_{(9-41)}$ partially blocks the inhibitory effect of serotonin on feeding. A possible mechanistic explanation for the connection between the CRH system and serotonin is supplied by a study which found that in rats, approximately half of the $\mathrm{CRH}$-containing neurons in the paraventricular nucleus of the hypothalamus co-expressed 5- $\mathrm{HT}_{2 \mathrm{C}}$ mRNA. Genetic inactivation of $5-\mathrm{HT}_{2 \mathrm{C}}$ downregulated $\mathrm{CRH}$ mRNA expression and blunted $\mathrm{CRH}$ and corticosterone release after 5-HT administration (Heisler et al., 2007).

Most studies of effects of serotonin and SSRI effects on feeding behaviour have used very high concentration of SSRI or injections of SSRI or serotonin into the test subject (De Pedro N et al.,

90 1998; Ortega et al., 2013). Mennigen et al (2010) included an environmentally relevant dose of fluoxetine $(540 \mathrm{ng} / \mathrm{l})$ but found no effect on food intake at this dose. While injection of active substances, or very high concentrations of active substances in the ambient water provide valuable control over the involved variables, they are less relevant in an environmental context where uptake, particle binding, photolysis and other factors influence the bioavailability of drugs and drug

95 metabolites. Furthermore, most studies done on the subject have used fluoxetine which is generally regarded as the least selective SSRI on the market. Apart from increasing extracellular serotonin 
levels, fluoxetine also increases extracellular levels of norepinephrine and dopamine (Bymaster et al., 2002). At least in the rat, blockade of dopamine receptors is known to decrease feeding (Sudakov and Bashkatova, 2013). In the fish sea bass (Dicentrarchus labrax), the dietary

100 administration of L-dopa (a dopamine precursor) has an inhibitory effect on feeding behaviour (Leal et al., 2013).

In Sweden and many other countries, citalopram is much more commonly used in the treatment of depression than fluoxetine. Citalopram is a racemic mixture and the S-enantiomer (known as

105 Escitalopram) is considered to be the most selective SSRI developed so far. The high citalopram usage and known potential to influence fish behaviour along with the poor degradation in STPs are good reasons for environmental concern. In this study we exposed three-spine sticklebacks to the environmentally relevant concentrations $0.15 \mu \mathrm{g} / \mathrm{l}$ and $1.5 \mu \mathrm{g} / \mathrm{l}$ citalopram dissolved in the ambient water for three weeks and measured the effects of this exposure on feeding behaviour. We found

110 that citalopram dissolved in the surrounding water had a pronounced inhibitory effect on the feeding behaviour of the three-spine stickleback which implicates that it should be considered an environmentally unsafe pharmaceutical.

\section{2. Materials and methods}

\subsection{Fish}

Three-spine sticklebacks were caught in the small harbour of Skåre $\left(55^{\circ} 22,30 \mathrm{~N} \mathrm{13} 3^{\circ} 3,18 \mathrm{E}\right)$ in southern Sweden in November 2013. A landing net with small mesh size was used. Adults of 5-6 $\mathrm{cm}$ overall length were chosen for absence of disease. The following day, the fish were transported

120 to Södertörn university where they were gradually acclimatised to fresh water and room temperature over a period of 48 hours. The fish were then divided by sex and housed in 400 litre holding tanks containing pieces of garden clay pots for shelters. The tanks were cleaned daily and fresh, aerated water was supplied continuously by a flow-through system. The fish were fed Chironomus larva (bloodworms) daily and kept on a 8:16 light:dark cycle to avoid sexual

125 maturation. Fish from the same catch were used in both experiments.

\subsection{Experimental setup}

Experiments took place between the beginning of December 2013 and mid-March 2014. On the first day of the experiment the fish were transferred to 9 litre exposure aquaria. There were 27

130 exposure aquaria standing side by side on five shelves. Black plastic sheets were placed between the aquaria to avoid visual contact between the aquaria. The exposure aquaria contained one piece of garden clay pot each for shelter. Fish were fed bloodworms to satiation daily.

\subsubsection{Experiment 1}

135 Fish were weighed and then moved to their exposure aquaria $\left(n_{\text {control }}=14\right.$ and $\left.n_{\text {treated }}=13\right)$ where they were kept solitarily. In order not to hurt the fish in the weighing process, they were weighed by lifting them from the water using a landing net, shaking them gently twice and then putting them in a pre-weighed water filled $500 \mathrm{ml}$ beaker. Citalopram bromide (kindly donated by Lundbeck A/S) dissolved in MilliQ water was added to every second aquarium to yield a final 140 nominal concentration of $1.5 \mu \mathrm{g} / \mathrm{l}$. The aquaria not receiving citalopram received a corresponding amount of MilliQ water. The water regime was semi-static and half of the water was exchanged with new room temperate and aerated water every second day. At the same time, the aquaria were cleaned from faeces and food residues. New citalopram solution or milliQ water was added to compensate for the amount removed during cleaning. A baseline reading of feeding behaviour was

145 done when the fish had been in the experimental aquaria for 24 hours. After the baseline reading, citalopram or milliQ water was added to the aquaria. Feeding behaviour was then recorded for 10 
minutes once a week for three weeks, starting one week after the beginning of the exposure.

Recording always took place between 9 a.m. and 1 p.m. When the fish were filmed, they had been food-deprived for approximately 24 hours. Recording of feeding behaviour was done with digital

150 video cameras and all staff left the room while recording. The analysis was performed manually afterwards, by counting the number of attacks on food items. While recording feeding behaviour, the aquaria were backlit using a light rack in order to see the fish and their food better.

\subsubsection{Experiment 2}

155 Like experiment 1, experiment 2 tested effects on feeding behaviour but included a lower, more environmentally relevant dose $(0.15 \mu \mathrm{g} / \mathrm{l})$ in addition to the $1.5 \mu \mathrm{g} / 1$ dose used in experiment 1 . In this experiment the fish were housed three fish in each aquarium and were treated with either $0 \mu \mathrm{g} / \mathrm{l}$, $0.15 \mu \mathrm{g} / 1$ or $1.5 \mu \mathrm{g} / \mathrm{l}$ for three weeks. Feeding behaviour was recorded during the two final days of the experiment. As in experiment 1, recording always took place between 9 a.m. and 1 p.m.

160 Experiment 2 included 36 fish housed in 12 different aquaria. two fish accidentally died during exposure and were thus excluded from analysis, which therefore included 34 fish. Most of the fish were recorded twice (I. e., one time each day). Recording was performed as in experiment 1 . No baseline recording was performed in this experiment. Instead, feeding rates were compared directly (see statistics section).

\subsection{Water samples}

In both experiment 1 and experiment 2, water samples were taken approximately one week into the exposure and by the end of the experiment. The water samples were analysed by HPLC-MS without any further sample preparation. Twenty-five $\mu \mathrm{L}$ was injected onto the HPLC column. The HPLC-MS

170 system used consisted of a Hewlett Packard 1100 series chromatograph (Palo Alto, California, USA) equipped with a Quatpump, a degasser, column oven (colcomp), an autosampler (ALS), and an MSD detector. Data were collected using the HP ChemStation software, version 6.03 (Palo Alto, California, USA). The analytical column was a reversed phase Kinetex C18 (Phenomenex, Værløse, Denmark) column (4.6 mm I.D. x $50 \mathrm{~mm}, 2.6 \mu \mathrm{m}$ particles). A linear gradient system was applied.

175 Eluent A consisted of $0.1 \%$ formic acid in MilliQ water and eluent B $0.1 \%$ formic acid in acetonitrile. The gradient was applied from $30 \%$ B to $90 \%$ B from $0-4$ minutes, maintained at $90 \%$ $\mathrm{B}$ for 1 minute and then returned to $30 \% \mathrm{~B}$ over 0.5 minutes. The flow-rate was $0.5 \mathrm{~mL} / \mathrm{minute}$. The MSD detector was equipped with an electrospray interface and used in positive mode for SIM detection of the mass: $\mathrm{m} / \mathrm{z}=325.1$. The fragmentor voltage was set to $100 \mathrm{~V}$. The voltage over the

180 capillary was kept at $5000 \mathrm{~V}$. The temperature of the nitrogen drying gas was set to $350{ }^{\circ} \mathrm{C}$ with a flow-rate of $9 \mathrm{~L} /$ minute. The nebulizer gas pressure was $60 \mathrm{psig}$.

\subsection{Statistics}

\subsubsection{Experiment 1}

185 In order to exclude individual differences a baseline trial was done for each fish before citalopram exposure began. All data from subsequent filming occasions were then normalised against this baseline, meaning that they were divided by the value obtained for the same fish in the baseline filming. Normalised data were then $\log (\mathrm{x}+1)$-transformed to reduce variation. Feeding behaviour was analysed in a mixed effects model with treatment as fixed factor and time as a random factor to 190 handle the repeated measurements on individual fishes at three different occasions. Tukey contrasts was used for post-hoc analysis. Weight gain was analysed using student's t-test. Basic data handling was done in Libreoffice 3.5.7.2. Statistical analysis was done in R using the lme4 package.

\subsubsection{Experiment 2}

195 In experiment 2 no baseline was recorded and the treated fish were compared directly to the control group using a mixed effects model. Tukey contrasts was used for post-hoc analysis. To handle the 
fact that the three fish in each aquarium and the two values originating from one fish were not independent samples, Aquarium and filming occasion were used as random factors in the mixed model.

\section{Results}

\subsection{Experiment 1}

All fish survived and appeared healthy throughout the trial. The average baseline value for the

205 control fish was 20 feeding strikes / 10 minutes. After exposure, the average number of feeding strikes for the control fish were 24.5, 14.5 and 17.6 for week one, two and three respectively. For the treated fish the average baseline value was 27.9 feeding strikes / 10 minutes. After one, two and three weeks, the average number of feeding strikes by the treated fish were 29.6, 21.4 and 23.1, respectively. When the number of feeding strikes were compared to baseline on an individual level,

210 the control fish increased their food consumption compared to baseline (average normalised consumption 2.09, 1.32 and 1.61 for the three filming occasions) while the food consumption of the treated fish was suppressed compared to baseline (average normalised consumption 1.13, 0.76 and 0.85 for the three filming occasions, Fig 1). When the normalised values were compared, there was a statistically significant effect of treatment $\left(\chi^{2}=4.45, \mathrm{p}=0.035\right)$ on feeding, i. e., the treated fish

215 reduced their food consumption over the exposure period. This effect became manifest at some point during the first week of exposure and was fairly constant during the entire experiment. There was no statistically significant effect of time by itself or interaction between treatment and time. The average body mass of treated and control fish at the onset of the experiment was $1.75 \mathrm{~g}$ and $1.69 \mathrm{~g}$ respectively $(\mathrm{N}=13$ for control and 14 for treated fish, $\mathrm{SD}=0.21$ and 0.28 , respectively).

220 During the experiment both groups gained weight. The treated fish gained $4.1 \%$ and the control fish gained 3.4\% on average (Fig 2). There was no statistically significant difference (two-tailed students t-test $p=0.76$ ) between treated and control fish in this respect. After euthanasia, the fish were dissected to check for intestinal parasites that may have influenced their feeding behaviour but no parasites were found. For the treated aquaria, the actual citalopram concentration in the water

225 ranged from $0.6 \mu \mathrm{g} / 1$ to $1.04 \mu \mathrm{g} / \mathrm{l}(\mathrm{n}=6$, mean $=0.79 \mu \mathrm{g} / \mathrm{l}, \mathrm{SD}=0.19)$. Samples from the control aquaria was also checked for citalopram pollution but no citalopram could be detected in those samples.

230 (Figure 1)

(Figure 2

\subsection{Experiment 2}

Experiment 2 tested the effects of both 0.15 and $1.5 \mu \mathrm{g} / 1$ on stickleback food consumption. As shown in fig 3 the average number of attacks were similar in the two treated groups. There was a significant effect of treatment $(\mathrm{p}<0.0001)$. In the post-hoc test, both treated groups consumed significantly less food than the control group ( $\mathrm{p}=0.001$ for the $0.15 \mu \mathrm{g} / \mathrm{l}$ and $\mathrm{p}=0.0002$ for the 1.5

$240 \mu \mathrm{g} / \mathrm{l}$ group). Analysis of water samples from the treated aquaria showed that actual concentrations in the $0.15 \mu \mathrm{g} / \mathrm{l}$ aquaria ranged between $0.07 \mu \mathrm{g} / 1$ and $0.1 \mu \mathrm{g} / 1(\mathrm{~N}=3$, mean $=0.09 \mu \mathrm{g} / 1, \mathrm{SD}=0.017)$ while the $1.5 \mu \mathrm{g} / \mathrm{l}$ aquaria contained between $0.86 \mu \mathrm{g} / \mathrm{l}$ and $1.15 \mu \mathrm{g} / \mathrm{l}(\mathrm{N}=3$, mean $=1.01 \mu \mathrm{g} / \mathrm{l}$, SD $=0.21$ ). No citalopram could be detected in water samples from the control aquaria.

\section{5 (Figure 3)}




\section{Discussion}

This study shows for the first time that environmentally relevant levels of the SSRI citalopram has a profound impact on feeding behaviour in fish. A substantial decrease in food intake was observed in both experiments and for both citalopram concentrations. In experiment 2 the reduction of food intake was comparable in the two treated groups, suggesting a flat dose-response curve in this dose interval. A flat dose-response curve of citalopram is consistent with the effects of citalopram on humans (Berney, 2005). This implies that the threshold concentration for effects of citalopram on feeding behaviour is likely to be lower than the concentrations used in this study, further stressing that environmental levels of citalopram can significantly affect nutrient intake in natural

260 ecosystems.

At the time of the first filming in experiment 1 the full effect of the treatment was already manifest which might explain the lack of effect of time and the lack of interaction between time and treatment in our mixed effects model. In humans, 14 days of administration is required for citalopram treatment to take full pharmaceutical effect (Hiemke and Härtter, 2000). For the threespine stickleback, this period is apparently shorter. The increased consumption in the control fish (Fig 1) was likely due to a short acclimatisation period before the baseline measurement. In the treated fish, this increase was small in the first filmed feeding and then proceeded to drop below baseline levels in subsequent readings.

There is a big discrepancy in the number of feeding strikes carried out by each fish between experiment 1 and experiment 2. In experiment 2, where the fish were held three fish in each aquarium the number of feeding strikes per fish during 10 minutes is approximately six times as high for the control fish and four times as high for the exposed fish compared to experiment 1

275 where the fish were held separately. This difference is unlikely to reflect a real difference in food intake but probably is a result of an increased number of failed strikes as a result of the very intense competition that ensues when food is added to an aquarium. The general stress imposed by fierce competition may also to some extent increase the number of feeeding strikes. Competition is likely to have a higher impact on control fish given citaloprams' dampening effect on competition (Lepage

280 et al., 2005), which may exacerbate the effect seen in experiment 2 . However, it must be kept in mind that three-spine sticklebacks are not solitary fish and that the situation in experiment 2 is in that respect more natural than the one in experiment 1.

In the present study feeding was suppressed by up to $37.5 \%$. Feeding is a key factor for individual 285 survival and growth (Elliott, 1976; Schrama et al., 2012) but it is also important for food web composition and can alter the composition of aquatic communities (Herrmann et al., 2012; Winkelmann et al., 2011). Feeding-mediated interaction is not limited to direct predation and individual growth but also involve competition for nutrients and other more complex interactions. Thus, if feeding rates are altered, it can potentially have a profound impact on affected ecosystems.

290 The three-spine stickleback is at an intermediate position in the food chain, where it acts both as a predator on zooplankton and as prey to larger fish and piscivorous birds. The serotonergic system is highly conserved between vertebrates and invertebrates and there are evidence that serotonin has similar appetite-supressing effects in invertebrates as in vertebrates (Falibene et al., 2012). If SSRIinduced feeding suppression is similar in other phylogenetic groups as in fish, the effects are hard to predict. SSRI have been shown to affect zooplancton as well (Campos et al., 2012). Thus, an increased abundance of zooplancton due to suppressed predation is one possible outcome but also a 
reduced fitness on all trophic levels. Selection pressures may be altered because predator avoidance becomes less important if those predators consume less. More studies are needed in order to clarify the ecological consequences of strong feeding suppression.

The present study shows that very low, environmentally relevant doses can affect feeding behaviour of fish. Previous studies have shown that high doses of SSRI can suppress feeding behaviour in both rodents (Grignaschi et al., 1998) and fish (De Pedro N et al., 1998; Mennigen et al., 2010; Ortega et al., 2013). Furthermore, in the field, fish are exposed to a wide range of SSRIs and their

305 metabolites (Metcalfe et al., 2010) which may retain pharmacological properties (Pawlowski et al., 1985), implying that the total environmental SSRI exposure is substantially higher than measurement of individual components will show. Apart from the additive effect of different SSRIs and SSRI metabolites that can be expected there is also a potential for more complex drug-drug interactions between SSRIs and other drugs (Hiemke and Härtter, 2000). In the field, fish are also

310 exposed to other psychiatric drugs, some of which have an opposite effect on feeding behaviour to that of citalopram (Brodin et al., 2013). It has been proposed that the anxiolytic effect of mood elevating drugs in itself leads to a higher food consumption (Brodin et al., 2013). Based on our results and on the fact that SSRI drugs are generally recognised as anxiolytics (Sackerman et al., 2010), it is likely that this potential effect is less important for feeding regulation than the appetite

315 suppression exerted by elevated serotonin levels. This prevalence of the effects exerted by rising serotonin levels may be important in the prediction of the effects of complex pharmaceutical mixtures in the field, where fish are exposed to a variety of different mood altering drugs of different classes.

320 In the present study we found that despite the strong effect of citalopram exposure on the number of feeding strikes, there was no effect on fish weight. The most likely explanation for this is that although the number of feeding strikes were only counted for ten minutes food usually remained in the aquarium, supplying the fish with abundant food for some time. Thus the fish were in effect fed ad libitum and possibly ingested enough food to gain weight even when the number of feeding

325 strikes was reduced. The reduced number of feeding strikes may have a greater significance in nature where food is limited. Further studies are needed to clarify the ecological significance of feeding suppression by SSRIs under natural conditions.

In conclusion, we found that both $0.15 \mu \mathrm{g} / 1$ and $1.5 \mu \mathrm{g} / 1$ citalopram has a clear impact on the 330 feeding behaviour of the three-spine stickleback, and together with other behavioural changes known to be caused by SSRIs, such as an increased affinity for surface dwelling and increased boldness it is likely to have a negative effect on ecosystems, at least locally. Further investigation of this field is necessary to correctly predict the ecological effects of SSRI exposure in the field.

Barbosa, A., Alves, F.L., Fim Pereira, A. de S., Ide, L.M., Hoffmann, A., 2012. Behavioral characterization of the alarm reaction and anxiolytic-like effect of acute treatment with fluoxetine in piauçu fish. Physiol. Behav. 105, 784-790. doi:10.1016/j.physbeh.2011.10.007

Berney, P., 2005. Dose-response relationship of recent antidepressants in the short-term treatment of depression. Dialogues Clin. Neurosci. 7, 249-62.

Boisvert, J.P., Boschuetz, T.J., Resch, J.M., Mueller, C.R., Choi, S., 2011. Serotonin mediated changes in corticotropin releasing factor mRNA expression and feeding behavior isolated to the hypothalamic paraventricular nuclei. Neurosci. Lett. 498, 213-217. doi:10.1016/j.neulet.2011.05.011

Brodin, T., Fick, J., Jonsson, M., Klaminder, J., 2013. Dilute Concentrations of a Psychiatric Drug Alter Behavior of Fish from Natural Populations. Science 339, 814-815. doi:10.1126/science. 1226850 
Bymaster, F., Zhang, W., Carter, P., Shaw, J., Chernet, E., Phebus, L., Wong, D., Perry, K., 2002. Fluoxetine, but not other selective serotonin uptake inhibitors, increases norepinephrine and dopamine extracellular levels in prefrontal cortex. Psychopharmacology (Berl.) 160, 353361. doi:10.1007/s00213-001-0986-x

Campos, B., Piña, B., Barata C, C., 2012. Mechanisms of Action of Selective Serotonin Reuptake Inhibitors in Daphnia magna. Environ. Sci. Technol. 46, 2943-2950. doi:10.1021/es203157f

Clissold, K.A., Choi, E., Pratt, W.E., 2013. Serotonin 1A, 1B, and 7 receptors of the rat medial nucleus accumbens differentially regulate feeding, water intake, and locomotor activity. Pharmacol. Biochem. Behav. 112, 96-103. doi:10.1016/j.pbb.2013.10.002

De Pedro N, Pinillos M L, Valenciano A I, Alonso-Bedate M, Delgado M J, 1998. Inhibitory Effect of Serotonin on Feeding Behavior in Goldfish: Involvement of CRF. Peptides 19, 505-511.

Elliott, J.M., 1976. The Energetics of Feeding, Metabolism and Growth of Brown Trout (Salmo trutta L.) in Relation to Body Weight, Water Temperature and Ration Size. J. Anim. Ecol. 45, 923. doi: $10.2307 / 3590$

Falibene, A., Rössler, W., Josens, R., 2012. Serotonin depresses feeding behaviour in ants. J. Insect Physiol. 58, 7-17. doi:10.1016/j.jinsphys.2011.08.015

Fick, J., Soederstrom, H., Lindberg, R.H., Phan, C., Tysklind, M., Larsson, D.G.J., 2009.

Contamination of Surface, Ground, and Drinking Water from Pharmaceutical Production.

Environ. Toxicol. Chem. 28, 2522-2527.

Gaworecki, K.M., Klaine, S.J., 2008. Behavioral and biochemical responses of hybrid striped bass during and after fluoxetine exposure. Aquat. Toxicol. 88, 207-213. doi:10.1016/j.aquatox.2008.04.011

Grignaschi, G., Invernizzi, R.W., Fanelli, E., Fracasso, C., Caccia, S., Samanin, R., 1998. Citalopram-induced hypophagia is enhanced by blockade of 5-HT ${ }_{1 \mathrm{~A}}$ receptors: role of 5-HT ${ }_{2 \mathrm{C}}$ receptors. Br. J. Pharmacol. 124, 1781-1787. doi:10.1038/sj.bjp.0702028

Heisler, L.K., Pronchuk, N., Nonogaki, K., Zhou, L., Raber, J., Tung, L., Yeo, G.S.H., O’Rahilly, S., Colmers, W.F., Elmquist, J.K., Tecott, L.H., 2007. Serotonin Activates the HypothalamicPituitary-Adrenal Axis via Serotonin 2C Receptor Stimulation. J. Neurosci. 27, 6956-6964. doi:10.1523/JNEUROSCI.2584-06.2007

Herrmann, P.B., Townsend, C.R., Matthaei, C.D., 2012. Individual and combined effects of fish predation and bed disturbance on stream benthic communities: a streamside channel experiment: Fish predation and flood disturbance. Freshw. Biol. 57, 2487-2503. doi:10.1111/fwb.12019

Hiemke, C., Härtter, S., 2000. Pharmacokinetics of selective serotonin reuptake inhibitors. Pharmacol. Ther. 85, 11-28. doi:10.1016/S0163-7258(99)00048-0

Hoyer, D., Hannon, J.P., Martin, G.R., 2002. Molecular, pharmacological and functional diversity of 5-HT receptors. Pharmacol. Biochem. Behav. 71, 533-554. doi:10.1016/S00913057(01)00746-8

Keltner, N., McAfee, K., Taylor, C., n.d. Mechanisms and treatments of SSRI-induced sexual dysfunction. Perspect. Psychiatr. Care 38, 111-116.

Kwon, J.-W., Armbrust, K.L., 2005. DEGRADATION OF CITALOPRAM BY SIMULATED SUNLIGHT. Environ. Toxicol. Chem. 24, 1618. doi:10.1897/04-522R.1

Larsson, D.G.J., de Pedro, C., Paxeus, N., 2007. Effluent from drug manufactures contains extremely high levels of pharmaceuticals. J. Hazard. Mater. 148, 751-755. doi:10.1016/j.jhazmat.2007.07.008

Leal, E., Fernández-Durán, B., Agulleiro, M.J., Conde-Siera, M., Míguez, J.M., Cerdá-Reverter, J.M., 2013. Effects of dopaminergic system activation on feeding behavior and growth performance of the sea bass (Dicentrarchus labrax): A self-feeding approach. Horm. Behav. 64, 113-121. doi:10.1016/j.yhbeh.2013.05.008

Lepage, O., Larson, E.T., Mayer, I., Winberg, S., 2005. Serotonin, but not melatonin, plays a role in 
shaping dominant-subordinate relationships and aggression in rainbow trout. Horm. Behav. 48, 233-242. doi:10.1016/j.yhbeh.2005.02.012

Mennigen, Lado, Zamora, Duarte-Guterman, Langlois, Metcalfe, Chang, Moon, Trudeau, 2010. Waterborne fluoxetine disrupts the reproductive axis in sexually mature male goldfish, Carassius auratus. Aquat. Toxicol. 100, 354-364. doi:10.1016/j.aquatox.2010.08.016

Metcalfe, C.D., Chu, S., Judt, C., Li, H., Oakes, K.D., Servos, M.R., Andrews, D.M., 2010. Antidepressants and their metabolites in municipal wastewater, and downstream exposure in an urban watershed. Environ. Toxicol. Chem. 29, 79-89. doi:10.1002/etc.27

Olsén, K.H., Ask, K., Olsén, H., Porsch-Hällström, I., Hallgren, S., 2014. Effects of the SSRI citalopram on behaviours connected to stress and reproduction in Endler guppy, Poecilia wingei. Aquat. Toxicol. 148, 113-121. doi:10.1016/j.aquatox.2013.12.032

Ortega, V.A., Lovejoy, D.A., Bernier, N.J., 2013. Appetite-suppressing effects and interactions of centrally administered corticotropin-releasing factor, urotensin I and serotonin in rainbow trout (Oncorhynchus mykiss). Front. Neurosci. 7. doi:10.3389/fnins.2013.00196

Painter, M.M., Buerkley, M.A., Julius, M.L., Vajda, A.M., Norris, D.O., Barber, L.B., Furlong, E.T., Schultz, M.M., Schoenfuss, H.L., 2009. Antidepressants at environmentally relevant concentrations affect predator avoidance behavior of larval fathead minnows (Pimephales promelas). Environ. Toxicol. Chem. 28, 2677-2684. doi:10.1897/08-556.1

Pawlowski, L., Nowak, G., G rka, Z., Mazela, H., 1985. Ro 11-2465 (cyan-imipramine), citalopram and their N-desmethyl metabolites: Effects on the uptake of 5-hydroxytryptamine and noradrenaline in vivo and related pharmacological activities. Psychopharmacology (Berl.) 86, 156-163. doi:10.1007/BF00431702

Pepels, P.P.L.M., 2004. Ontogeny of corticotropin-releasing factor and of hypothalamic-pituitaryinterrenal axis responsiveness to stress in tilapia (Oreochromis mossambicus; Teleostei). J. Exp. Biol. 207, 4479-4488. doi:10.1242/jeb.01316

Pérez Maceira, J.J., Mancebo, M.J., Aldegunde, M., 2014. The involvement of 5-HT-like receptors in the regulation of food intake in rainbow trout (Oncorhynchus mykiss). Comp. Biochem. Physiol. Part C Toxicol. Pharmacol. 161, 1-6. doi:10.1016/j.cbpc.2013.12.003

Perreault, H., Semsar, K., Godwin, J., 2003. Fluoxetine treatment decreases territorial aggression in a coral reef fish. Physiol. Behav. 79, 719-724. doi:10.1016/S0031-9384(03)00211-7

Ricci, L.A., Melloni, R.H., 2012. Repeated fluoxetine administration during adolescence stimulates aggressive behavior and alters serotonin and vasopressin neural development in hamsters. Behav. Neurosci. 126, 640-653. doi:10.1037/a0029761

Sackerman, J., Donegan, J.J., Cunningham, C.S., Nguyen, N.N., Lawless, K., Long, A., Benno, R.H., Gould, G.G., 2010. Zebrafish Behavior in Novel Environments; Effects of Acute Exposure to Anxiolytic Compounds and Choice of Danio rerio Line. Int. J. Comp. Psychol. $23,43-61$.

Schrama, J.W., Saravanan, S., Geurden, I., Heinsbroek, L.T.N., Kaushik, S.J., Verreth, J.A.J., 2012. Dietary nutrient composition affects digestible energy utilisation for growth: a study on Nile tilapia (Oreochromis niloticus) and a literature comparison across fish species. Br. J. Nutr. 108, 277-289. doi:10.1017/S0007114511005654

Steffens, S.M., Beckman, D., Faria, M.S., Marino-Neto, J., Paschoalini, M.A., 2010. WAY100635 blocks the hypophagia induced by $8-\mathrm{OH}-\mathrm{DPAT}$ in the hypothalamic nuclei. Physiol. Behav. 99, 632-637. doi:10.1016/j.physbeh.2010.01.024

Sudakov, S.K., Bashkatova, V.G., 2013. Effect of Peripheral D2 Dopamine Receptor Antagonist Domperidone on Metabolism, Feeding Behavior, and Locomotor Activity of Rats. Bull. Exp. Biol. Med. 155, 705-707. doi:10.1007/s10517-013-2231-0

Van Praag, H.M., 1977. New Evidence of Serotonin-Deficient Depressions. Neuropsychobiology 3, 56-63. doi:10.1159/000117590

Vasskog, T., Anderssen, T., Pedersen-Bjergaard, S., Kallenborn, R., Jensen, E., 2008. Occurrence of 
selective serotonin reuptake inhibitors in sewage and receiving waters at Spitsbergen and in Norway. J. Chromatogr. A 1185, 194-205. doi:10.1016/j.chroma.2008.01.063

Vasskog, T., Berger, U., Samuelsen, P.-J., Kallenborn, R., Jensen, E., 2006. Selective serotonin reuptake inhibitors in sewage influents and effluents from Tromsø, Norway. J. Chromatogr. A 1115, 187-195. doi:10.1016/j.chroma.2006.02.091

Ward, A., Comer, S., Haney, M., Fischman, M., Foltin, R., 1999. Fluoxetine-Maintained Obese HumansEffect on Food Intake and Body Weight. Physiol. Behav. 66, 815-821. doi:10.1016/S0031-9384(99)00020-7

Winkelmann, C., Hellmann, C., Worischka, S., Petzoldt, T., Benndorf, J., 2011. Fish predation affects the structure of a benthic community: Fish affect benthic community structure. Freshw. Biol. 56, 1030-1046. doi:10.1111/j.1365-2427.2010.02543.x

Woldegiorgis, A., 2011. SSLs mätningar av läkemedel i vatten och korresponderande regional försäljning av läkemedel i storstockholm. 